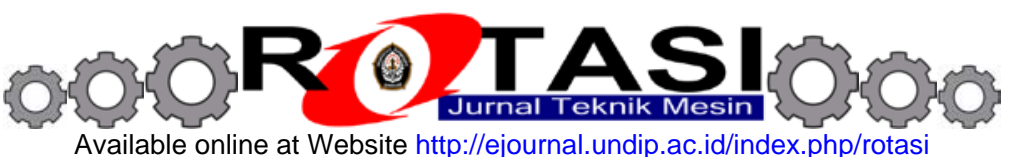

\title{
Uji Terbang Autonomous Low Cost Fixed Wing UAV Menggunakan PID Compensator
}

\author{
*Mochammad Ariyanto, Joga D. Setiawan, Munadi, Teguh parabowo \\ Departemen Teknik Mesin, Fakultas Teknik Universitas Diponegoro \\ Jl.Prof.H.Soedarto, S.H.Tembalang, Tembalang, Semarang \\ *E-mail: mochammad_ariyanto@ft.undip.ac.id
}

\begin{abstract}
Abstrak
Pengguna UAV pada umumnya terbagi ke dalam dua kelompok, yaitu pengguna yang menggunakan UAV buatan pabrik dan pengguna yang membuat UAV sendiri. Pengguna yang membangun UAV sendiri harus mendesain, menghitung performa aerodinamika, dan membuat (memanufaktur) UAV-nya sendiri. Selain itu, mereka harus menentukan komponen-komponen mekanis dan elektris dimana yang dibutuhkan agar UAV dapat beroperasi sesuai dengan performa yang diharapkan. Membangun UAV membutuhkan biaya yang lebih murah daripada membeli UAV buatan pabrik. Pada pengembangan UAV diperlukan proses desain, pembuatan (manufaktur), dan uji terbang berkali-kali hingga performa UAV saat terbang mengikuti tracking secara autonomous yang baik. Pada penelitian ini, sebuah fixedwing UAV akan didesain dan dibuat dengan menggunakan material yang murah (low cost). Setelah fixed wing UAV telah dibuat, maka akan dilakukan pengujian terbang menggunakan kontrol PID. Fixed wing UAV yang telah dikembangkan akan dilakukan uji terbang secara autonomous untuk mengikuti tracking terhadap perintah yang diberikan. Perintah Trajectory yang harus diikuti oleh UAV berupa persegi panjang dengan ketinggian $100 \mathrm{~m}$. Berdasarkan hasil uji terbang, sebuah fixed-wing UAV telah berhasil didesain dan dibuat dengan material yang murah dan dapat melakukan terbang secara autonomus mengikuti perintah trajectory yang diberikan menggunakan PID compensator.
\end{abstract}

Kata kunci: low cost, fixed wing, UAV, uji terbang, PID

\section{Pendahuluan}

Seiring dengan kemajuan teknologi di bidang sistem elektronik dan komputer, keperluan penerbangan di dunia sudah menjadi lebih praktis, lebih efektif, lebih aman, dan lebih efisien daripada sebelumnya berkat kehadiran unmanned aerial vehicle (UAV) atau pesawat tanpa awak. Pada awalnya, orang-orang menggunakan pesawat berawak untuk keperluan tertentu, misalnya pemantauan arus lalu lintas, keperluan pemetaan jalan, pemantauan daerah bencana, pencarian korban bencana alam, fotografi, riset, eksplorasi sumber daya alam, militer, dan lain-lain. Penggunaan pesawat berawak tersebut membutuhkan biaya yang tidak sedikit, ditambah peluang terjadinya kecelakaan yang akan selalu ada. Kini, UAV dapat melakukan keperluan-keperluan penerbangan tersebut dengan biaya yang lebih murah, kinerja lebih efektif, dan resiko kecelakaan yang jauh lebih kecil. Karena itu, UAV di dunia dewasa ini semakin marak digunakan [1].

Secara umum, UAV dapat diklasifikasikan berdasarkan jenis sayap dan ukurannya. Berdasarkan jenis sayap, UAV diklasifikasikan ke dalam rotary wing, fixed-wing, dan flapping wing. Berdasarkan ukurannya, UAV diklasifikasikan ke dalam very small UAV, small UAV, medium UAV, dan large UAV. Pada UAV jenis fixed wing mendapatkan lift yang dihasilkan oleh sayap yang terpasang secara stasioner (fixed). Sayap menghasilkan lift yang cukup untuk terbang ketika UAV mencapai airspeed tertentu. Agar sayap tetap menghasilkan lift yang cukup, airspeed didapat menggunakan thrust yang dihasilkan oleh propeller yang terhubung ke mesin/motor [2].

Kemampuan autonomous adalah robot (dalam hal ini UAV) mampu melaksanakan perintah tanpa membutuhkan masukan (input) yang eksplisit dari manusia [3]. Misalnya, UAV dapat terbang dari satu titik ke titik lain (waypoint) yang telah ditentukan tanpa adanya masukan kontrol dari pilot selama UAV tersebut dalam perjalanan. Selain itu, UAV mampu menjalankan perintah tersebut dengan stabil, dengan kecepatan yang konstan, meskipun pada saat terbang, UAV mendapat gangguan angin (gust).

Sistem komunikasi UAV terdiri dari ground control station, wireless telemetry radio, dan radio control. Ground control station (GCS) adalah suatu komputer yang ada di darat yang berkomunikasi dengan UAV menggunakan suatu software melalui wireless telemetry. Wireless telemetry radio adalah suatu alat komukasi antara UAV dan GCS. Wireless telemetry radio terdiri dari dua bagian, yaitu transmitter yang dipasang pada UAV dan receiver yang dipasang di darat. Meskipun UAV dapat terbang secara autonomous berkat adanya autopilot controller board, radio control tetap dibutuhkan. Radio control dibutuhkan untuk mengendalikan UAV pada mode Manual maupun pada mode semiautonomous, misalnya mode fly by wire (FBW) [4].

Pada penelitian ini, akan didesain dan dikembangkan sebuah fixed-wing $U A V$ dengan menggunakan material yang murah (low cost). Uji terbang dilakukan beberapa kali hingga UAV yang dibuat mempunyai performa tracking yang baik. Untuk uji terbang dalam penelitian ini diberikan perintah trajectory yang berebentuk persegi panjang dengan ketinggian terbang $100 \mathrm{~m}$. 


\section{Prototip Fixed Wing UAV}

Pada penelitian ini menggunakan konfigurasi sayap konvensional, horizontal tail berada di bagian belakang fuselage. Horizontal tail dan vertical tail dapat ditempelkan satu sama lain. Bagian belakang fuselage dapat disederhanakan dalam bentuk batang aluminium guna mengurangi berat sistem. Karena batang aluminium tersebut, horizontal tail dan vertical tail dapat dipasang dengan cukup kuat tanpa perlu dudukan khusus, cukup dengan menggunakan klem.

Pada penelitian ini menggunakan konfigurasi high wing, konfigurasi ini pada bagian tengah sayap dapat dibuat untuk tidak memotong bagian atas fuselage. Sayap dapat diletakkan tepat di atas fuselage dengan menggunakan suatu dudukan sehingga sayap dapat terpasang dengan baik pada fuselage. Untuk mengencangkan posisi sayap, sayap diikat pada fuselage dengan menggunakan suatu tali lentur. Tidak perlunya memotong fuselage guna mempermudah proses pembuatan UAV dan juga tidak mengurangi kekuatan dari fuselage.

Pada UAV dengan konfigurasi high wing, center of gravity terletak di bawah sayap. Hal ini menyebabkan adanya keel effect, atau efek pendulum, di mana jika UAV terkena gangguan angin dari samping, UAV cenderung melakukan roll kembali ke posisi semula [5]. Pada konfigurasi mid wing dan low wing, efek pendulum tersebut lebih kecil. Dengan kata lain, UAV dengan konfigurasi high wing memiliki lateral stability yang lebih baik daripada konfigurasi mid wing dan low wing.

Letak sayap yang tinggi akan memudahkan pelempar untuk menggenggam fuselage pada saat proses hand launch. Hal tersebut dapat memperkecil resiko kegagalan hand launch. Semakin rendah letak sayap, maka semakin sulit pelempar untuk menggenggam UAV dengan baik. Semakin tinggi letak sayap, maka semakin besar pula ground clearance-nya. Yang dimaksud dengan ground clearance adalah jarak vertikal antara sayap dengan permukaan tanah pada saat UAV berada di atas permukaan tanah. Semakin besar ground clearance maka semakin kecil kemungkinan sayap terbentur permukaan tanah pada saat landing. Dengan kata lain, kemungkinan kerusakan struktur sayap dan servo juga semakin kecil. Berdasarkan pertimbangan-pertimbangan ini, konfigurasi yang dipilih adalah konfigurasi high wing.

Fuselage yang terbuat dari kayu balsa memiliki berat yang paling ringan dibandingkan dua material yang lain. Kayu balsa yang ada di pasaran umumnya berbentuk papan dengan dimensi $100 \mathrm{~cm}$ x $10 \mathrm{~cm}$ dengan ketebalan yang berbeda-beda. Untuk memotong kayu balsa menjadi bentuk yang diinginkan, cutter dapat digunakan. Namun, proses pengerjaannya akan memakan waktu yang sangat lama. Akan jauh lebih mudah jika keseluruhan struktur didesain terlebih dahulu menggunakan software CAD. Dengan hasil desain tersebut, kita bisa memotong kayu balsa menggunakan mesin laser cutting. Namun, penggunaan jasa laser cutting akan memakan biaya yang mahal. Terlebih, untuk membuat satu fuselage dengan ukuran yang sama, material kayu balsa relatif lebih mahal jika dibandingkan dengan dua material yang lain. Kayu balsa juga tidak mudah ditemui di pasaran dan biasanya hanya tersedia di tokotoko hobi tertentu. Selain itu, karena UAV pada penelitian ini harus dapat mendarat di atas permukaan yang kasar dan tanpa landing gear, maka struktur kayu balsa sangat rentan mengalami keretakan.

Fuselage yang terbuat dari foam mudah dibentuk dengan menggunakan cutting wire, cutter, dan amplas. Foam mudah didapat di pasaran dengan harga yang relatif murah. Namun, agar struktur fuselage dari material foam cukup kuat. Hal-hal tersebut dapat membuat fuselage menjadi lebih berat. Mengenai persoalan landing di atas permukaan yang kasar dan tanpa landing gear, material foam yang sudah diperkuat tidak rentan retak atau patah, namun material tersebut bisa terdeformasi.

Salah satu benda yang kuat, ringan, murah, mudah didapat di pasaran, dan cocok untuk dijadikan fuselage adalah tabung gambar (drawing tube). Tabung gambar pada umumnya terbuat dari plastik keras atau PVC (polyvinyl chloride). Dengan diameter sebesar $8 \mathrm{~cm}$, tabung gambar mempunyai ruang yang cukup untuk baterai, autopilot controller board, dan komponen-komponen lain yang dibutuhkan untuk menjalankan misi penelitian.

Untuk mengurangi berat dan mempermudah pemasangan horizontal tail dan vertical tail, bagian fuselage yang berada di belakang sayap tidak menggunakan tabung gambar, melainkan silinder aluminium. Agar fuselage lebih tahan terhadap keretakan pada saat landing, bagian bawah fuselage diberi suatu material karet sebagai impact-absorbing material. Pada penelitian ini, jenis material fuselage yang dipilih adalah tabung gambar plastik dan silinder aluminium.

Untuk komfigurasi lokasi propeller, konfigurasi tractor merupakan yang paling mudah dibuat karena tidak membutuhkan dudukan khusus untuk instalasi motor pada bagian depan fuselage. Fuselage yang akan digunakan pada penelitian ini adalah sebuah tabung gambar yang bagian depannya merupakan permukaan datar yang cukup kuat untuk instalasi motor. Tidak dibutuhkannya dudukan khusus untuk instalasi motor berarti tidak menambah berat UAV. Letak propeller yang berada di depan fuselage juga membuat proses hand launch menjadi aman karena tangan pelempar berada jauh dari propeller. Namun, karena letak sumbu putar propeller sejajar dengan sumbu simetri fuselage (secara longitudinal), jarak dari tepi propeller ke tanah (ground clearance) menjadi minim. Hal tersebut memperbesar resiko propeller patah pada saat landing. Hasil akhir desain dan prototip fixed wing UAV dapat ditunjukkan seperti pada Gambar 1, dan Gambar 2.

\section{Uji Terbang mengikuti PerintahTrajectory}

Setelah fixed wing UAV seperti yang ditunjukkan pada Gambar 2 telah berhasil dikembangkan dan dibuat menggunakan material yang murah dan mudah untuk dicari. Langkah selanjutnya adalah melakukan uji terbang. Fligh controller board pada UAV ini menggunakan ArduPilot board. 


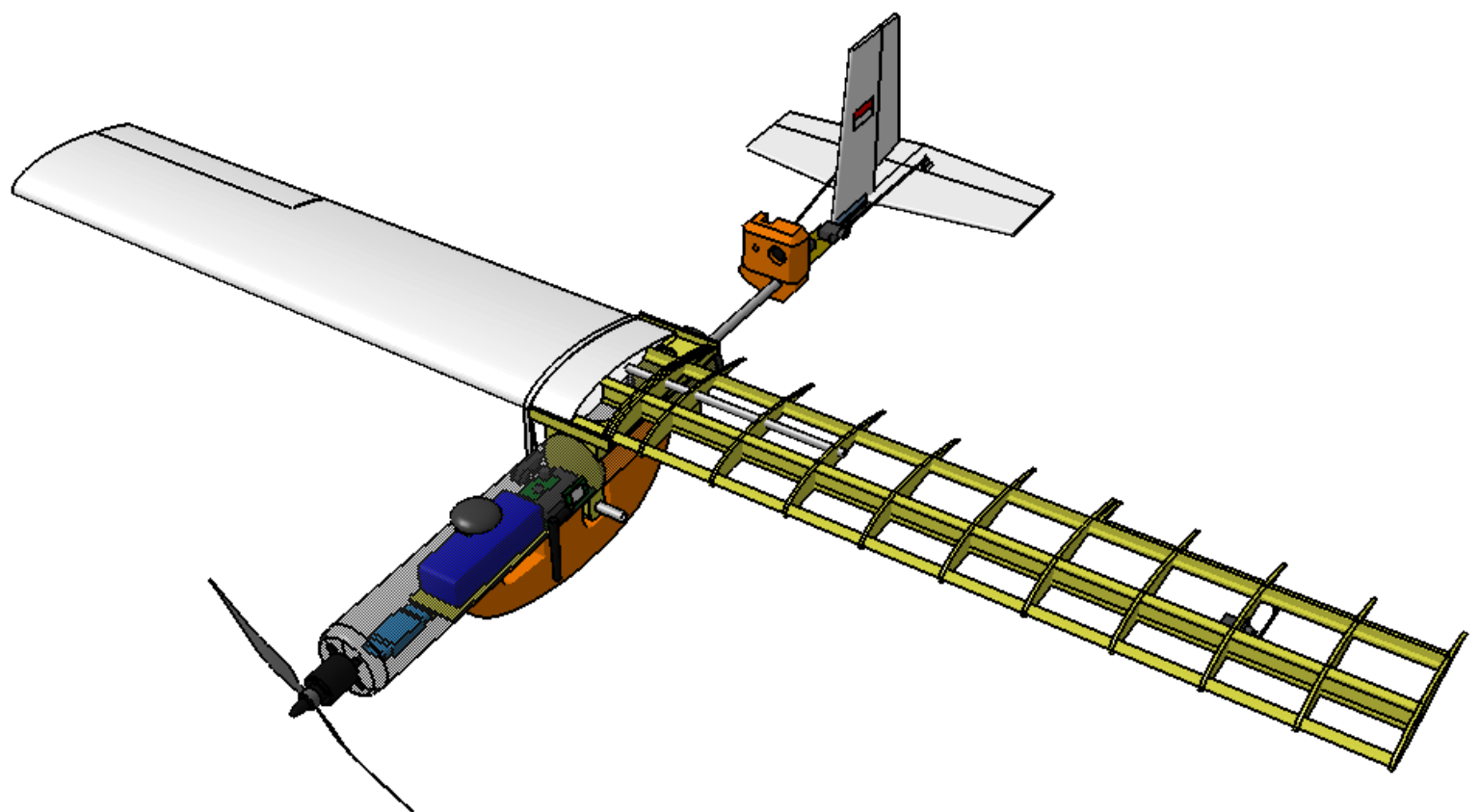

Gambar 1. Hasil desain fixed wing UAV.

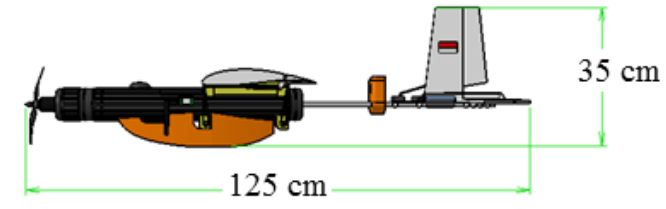

A

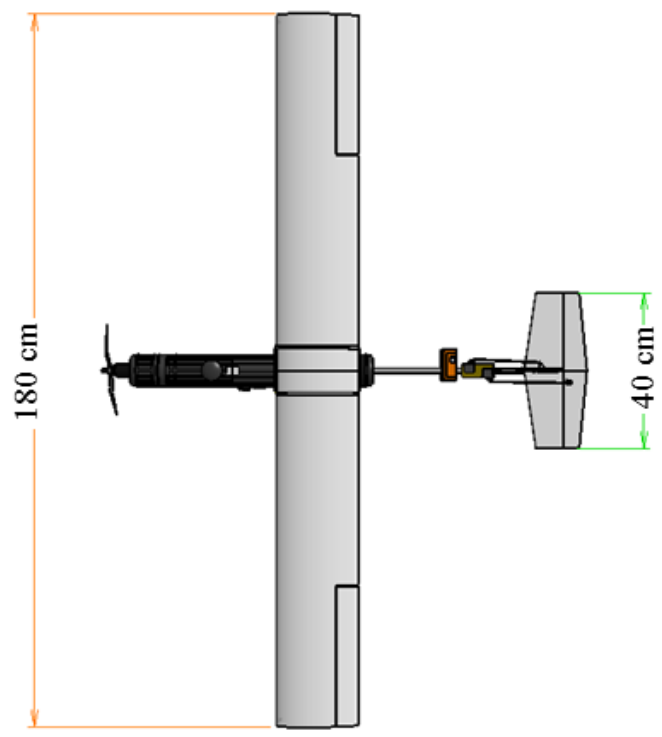

B

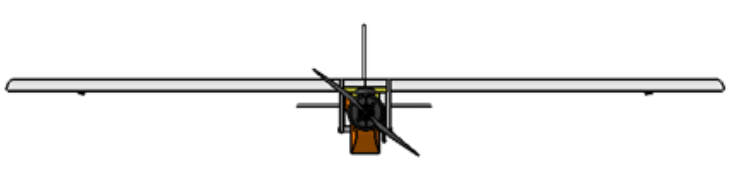

$\mathrm{C}$

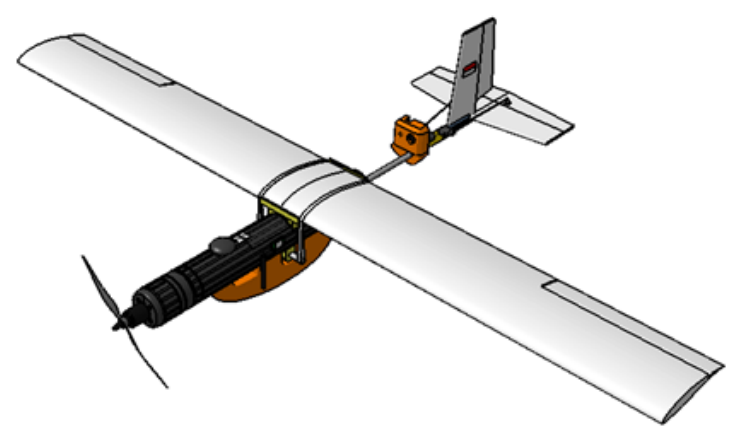

$\mathrm{D}$

Gambar 2. Fixed UAV yang dihasilkan (A) Tampak samping, (B) tampak atas, (C) tampak depan, dan (D) tampak isometrik

Pada uji terbang ini, UAV terbang pada mode Auto dilakukan di atas ketinggian $100 \mathrm{~m}$ dan mengelilingi track sebanyak lima kali. Gambar 3 menunjukkan UAV sedang take off pada saat uji terbang dengan menggunakan hand launch. Gambar 4 menunjukkan UAV sedang terbang pada mode Autonomous di ketinggian 100 m. Gambar 5 menunjukkan tampilan first person view saat mode Autonomous di ketinggian $100 \mathrm{~m}$. Perintah trajectory berupa persegi panjang seperti yang ditunjukkan pada Gambar 6 dengan garis yang berwarna kuning. 


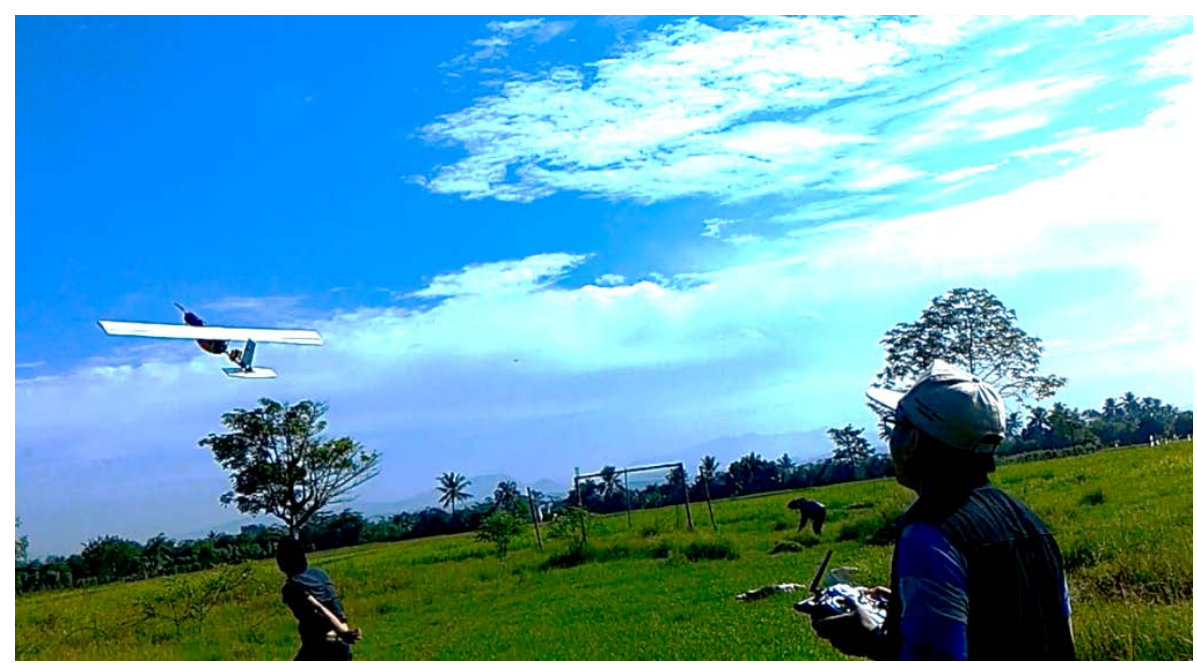

Gambar 3. UAV sedang take off dengan hand launch pada uji terbang

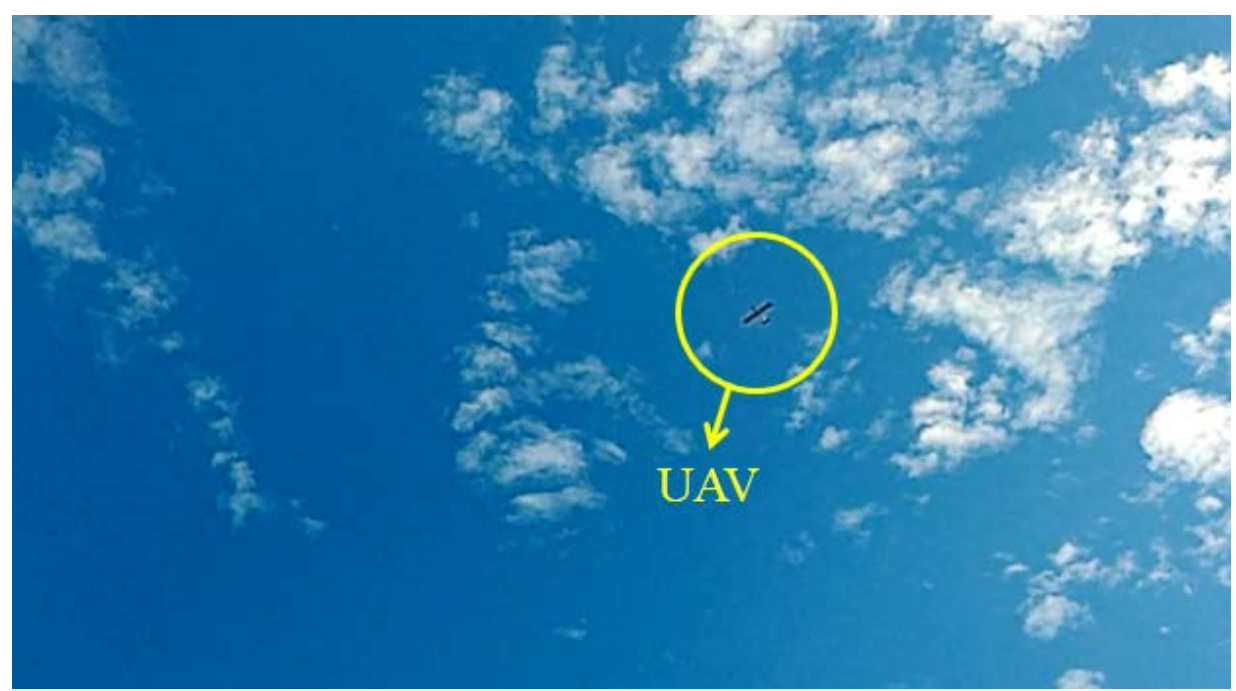

Gambar 4. UAV sedang terbang pada mode Auto di ketinggian $100 \mathrm{~m}$.

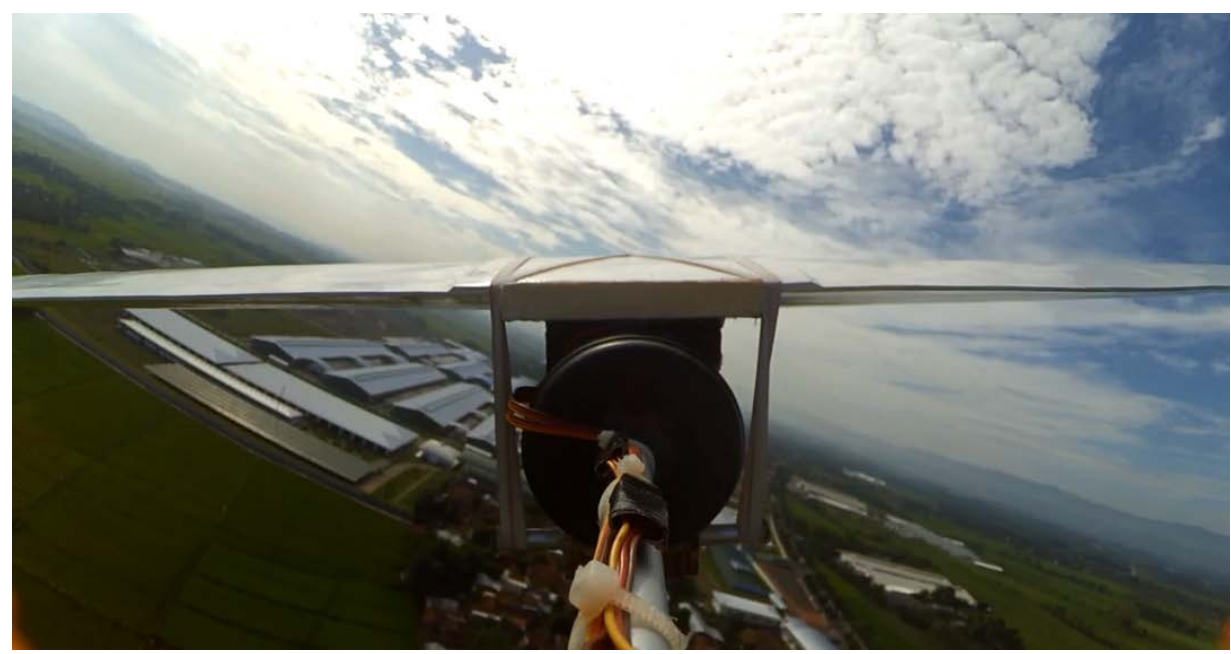

Gambar 5. Tampilan first person view saat mode Auto di ketinggian $100 \mathrm{~m}$.

Pada uji Penerbangan ini, nilai K_P pada roll controller sebelumnya adalah 0,750. Pada uji penerbangan kali ini, nilai K_P pada roll controller diturunkan $20 \%$ sehingga nilainya menjadi 0,600 . Sementara itu, K_I dan K_D pada roll controller masih sama seperti penerbangan sebelumnya, yaitu menggunakan pengaturan default. Tabel 1 menunjukkan pengaturan roll, pitch, dan navigation controller pada uji terbang yang dilakukan untuk mengikuti perintah trajectory. 
Tabel 1. Pengaturan konstanta gain pada roll, pitch, dan navigation controller uji terbang

\begin{tabular}{|c|c|c|}
\hline Controller & Parameter & Nilai \\
\hline \multirow{3}{*}{ Roll } & K_P & 0,600 \\
\cline { 2 - 3 } & K_I & 0,05 \\
\cline { 2 - 3 } & K_D & 0,02 \\
\hline \multirow{3}{*}{ Pitch } & K_P & 0,405 \\
\cline { 2 - 3 } & K_I & 0,04 \\
\cline { 2 - 3 } & K_D & 0,02 \\
\hline Navigation & Turn Control Period & 15 \\
\hline Navigation & Waypoint Radius (m) & 20 \\
\hline
\end{tabular}

Pada Gambar 6 menunjukkan tampilan dua dimensi flight path UAV pada mode Autonomopus pada saat uji terbang. Pada Gambar 6 juga memperlihatkan bahwa osilasi flight path terhadap track masih terjadi khususnya osilasi terjadi disaat perintah trajectory berbelok sebesar $90^{\circ}$. Setelah beberapa saat dari belokan $90^{\circ}$ maka osilasi yang terjadi akan semakin mengecil.Uji terbang ini dilakukan sebanyak lima kali mengikuti perintah trajectory.

Sementara pada Gambar 7 menunjukkan tampilan tiga dimensi flight path UAV pada mode Autonomous yang diambil dari software Google Earth. Di sini, yang ditampilkan hanya flight path, sementara track tidak ditampilkan. Pada tampilan Gambar 7 trajectory dari fixed wing UAV dapat terlihat menjadi lebih jelas dibandingkan dengan Gambar 6. Pada pengujian terbang di atas $100 \mathrm{~m}$ kecepatan angin tidak memberikan pengaruh yang signifikan terhadap trajectory dari fixed wing UAV.

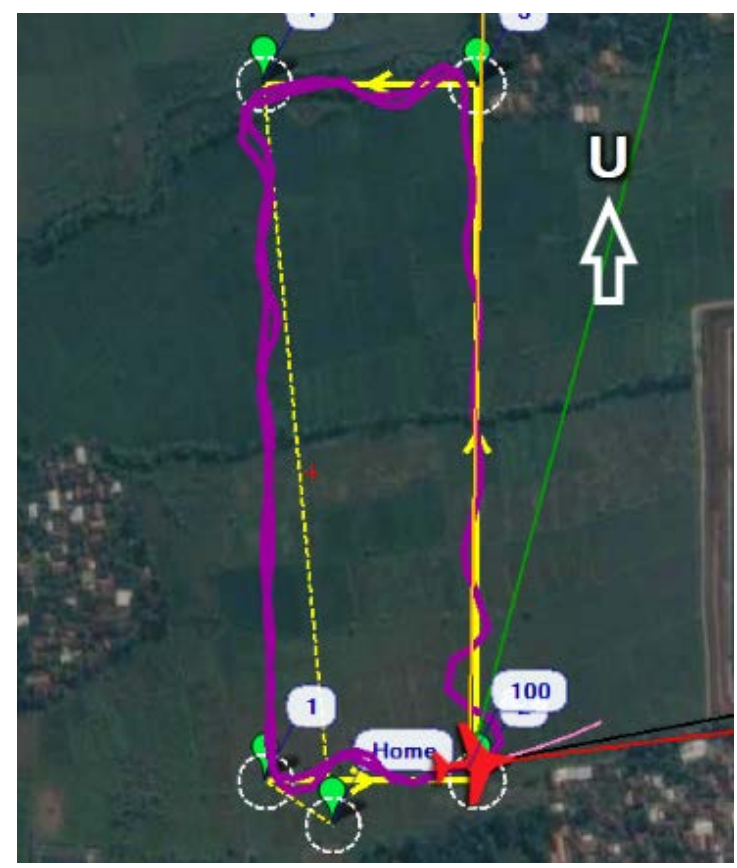

Gambar 6. Tampilan dua dimensi flight path following UAV pada mode Auto.

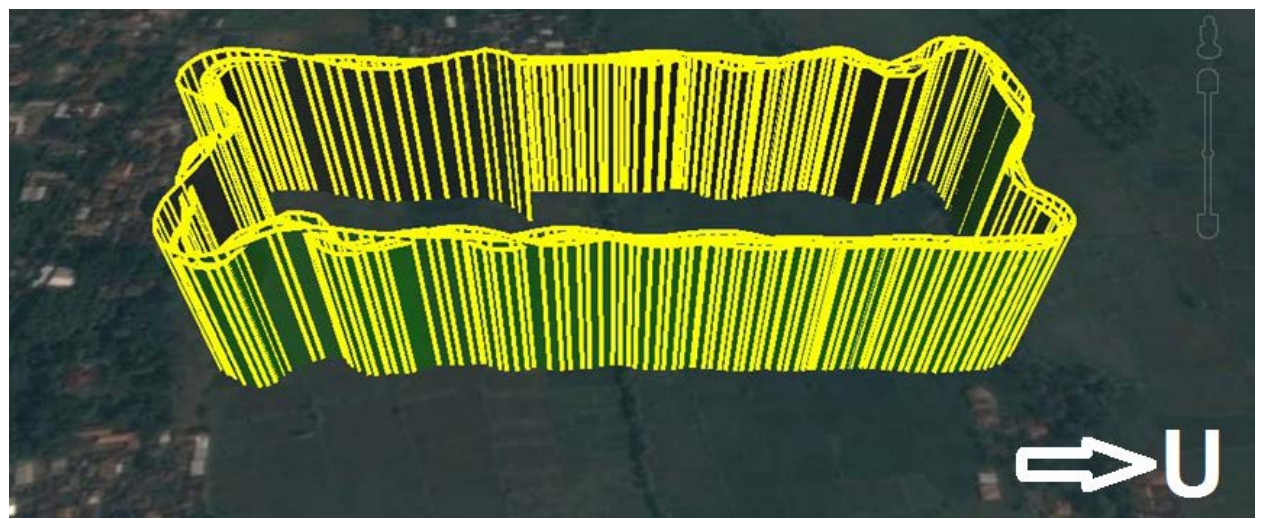

Gambar 7. Tampilan tiga dimensi flight path UAV pada mode Auto yang diambil dari software Google Earth. 


\section{Kesimpulan}

Sebuah fixed-wing UAV telah didesain dan dibuat dengan menggunakan material yang murah dan dapat melakukan terbang secara autonomus mengikuti track yang berebentuk persegi panjang. UAV tersebut juga dilengkapi oleh kamera yang dapat digunakan untuk pengambilan baik gambar maupun video. Setelah dilaksanakan uji terbang, UAV memiliki performa tracking yang baik mengikuti perintah dengan pengaturan roll, pitch, dan navigation controller seperti yang telah disimpulkan pada Tabel 1. Material yang digunakan dalam membuat UAV akan dipilih yang lebih ringan, lebih kuat, lebih murah, dan lebih mudah untuk dimanufaktur.

\section{Referensi}

[1] Ashworth, A. 2015. "Rise of the Commercial Drone”. https://bluefletch.com/blog/ rise-of-the-commercial-drone/ , diakses: 8 November 2016.

[2] Kendall. 2012. “Difference Between Fixed-Wing Aircraft and a Rotary Wing Aircraft”. http://www.aerolink.es/blog/difference-between-fixed-wing-aircr aft-and-a-rotary-wing-aircraft/, diakses: 9 November 2016.

[3] Bekey, G. 2005. “Autonomous Robots”. https://mitpress.mit.edu/books/autonomous-robots, diakses: 12 November 2016.

[4] ArduPilot Developer Team. 2016. “Auto Mode”. http://ardupilot.org/plane/docs/auto -mode.html\#auto-mode , diakses: 16 November 2016.

[5] Adamone. 2003. “Beginners' Guide: Electric Motors”. http://adamone.rchomepage. com/guide5.htm , diakses: 8 November 2016.

\section{Ucapan Terima Kasih}

Penelitian ini didukung oleh Hibah Bersaing DIPA Fakultas Teknik Undip Tahun Anggaran 2017. 